\title{
ICU admission body composition: skeletal muscle, bone, and fat effects on mortality and disability at hospital discharge-a prospective, cohort study
}

Ariel Jaitovich ${ }^{1,2^{*}}$, Camille L. Dumas ${ }^{3}$, Ria Itty ${ }^{1}$, Hau C. Chieng ${ }^{1}$, Malik M. H. S. Khan ${ }^{1,4}$, Ali Naqvi ${ }^{1}$, John Fantauzzi ${ }^{3}$, Jesse B. Hall ${ }^{5}$, Paul J. Feustel ${ }^{6}$ and Marc A. Judson ${ }^{1}$

\begin{abstract}
Background: Reduced body weight at the time of intensive care unit (ICU) admission is associated with worse survival, and a paradoxical benefit of obesity has been suggested in critical illness. However, no research has addressed the survival effects of disaggregated body constituents of dry weight such as skeletal muscle, fat, and bone density.

Methods: Single-center, prospective observational cohort study of medical ICU (MICU) patients from an academic institution in the USA. Five hundred and seven patients requiring CT scanning of chest or abdomen within the first $24 \mathrm{~h}$ of ICU admission were evaluated with erector spinae muscle (ESM) and subcutaneous adipose tissue (SAT) areas and with bone density determinations at the time of ICU admission, which were correlated with clinical outcomes accounting for potential confounders.

Results: Larger admission ESM area was associated with decreased odds of 6-month mortality (OR per $\mathrm{cm}^{2}, 0.96$; $95 \% \mathrm{Cl}, 0.94-0.97 ; p<0.001)$ and disability at discharge (OR per $\left.\mathrm{cm}^{2}, 0.98 ; 95 \% \mathrm{Cl}, 0.96-0.99 ; p=0.012\right)$. Higher bone density was similarly associated with lower odds of mortality (OR per $100 \mathrm{HU}, 0.69 ; 95 \% \mathrm{Cl}, 0.49-0.96 ; p=0.027$ ) and disability at discharge (OR per $100 \mathrm{HU}, 0.52 ; 95 \% \mathrm{Cl}, 0.37-0.74 ; p<0.001)$. SAT area was not significantly associated with these outcomes' measures. Multivariable modeling indicated that ESM area remained significantly associated with 6-month mortality and survival after adjusting for other covariates including preadmission comorbidities, albumin, functional independence before admission, severity scores, age, and exercise capacity.

Conclusion: In our cohort, ICU admission skeletal muscle mass measured with ESM area and bone density were associated with survival and disability at discharge, although muscle area was the only component that remained significantly associated with survival after multivariable adjustments. SAT had no association with the analyzed outcome measures.
\end{abstract}

Keywords: Skeletal muscle, Adipose tissue, Bone density, Critical illness, Mortality

\footnotetext{
* Correspondence: jaitova@amc.edu

'Division of Pulmonary and Critical Care Medicine, Albany Medical College, Albany, NY, USA

${ }^{2}$ Department of Molecular and Cellular Physiology, Albany Medical College, 47 New Scotland Av, Albany, NY, USA

Full list of author information is available at the end of the article
}

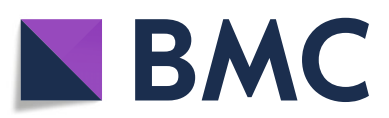

() The Author(s). 2020 Open Access This article is licensed under a Creative Commons Attribution 4.0 International License, which permits use, sharing, adaptation, distribution and reproduction in any medium or format, as long as you give appropriate credit to the original author(s) and the source, provide a link to the Creative Commons licence, and indicate if changes were made. The images or other third party material in this article are included in the article's Creative Commons licence, unless indicated otherwise in a credit line to the material. If material is not included in the article's Creative Commons licence and your intended use is not permitted by statutory regulation or exceeds the permitted use, you will need to obtain permission directly from the copyright holder. To view a copy of this licence, visit http://creativecommons.org/licenses/by/4.0/. The Creative Commons Public Domain Dedication waiver (http://creativecommons.org/publicdomain/zero/1.0/) applies to the data made available in this article, unless otherwise stated in a credit line to the data. 


\section{Background}

Skeletal muscle dysfunction, encompassing wasting and weakness $[1,2]$, is associated with poor intensive care unit (ICU) outcomes including worse survival [3], need for mechanical ventilation, and higher readmission rate [4-6]. In many ICU survivors, muscle dysfunction persists for years [6, 7], and we have recently reported that reduced pectoralis muscle mass at the time of ICU admission is independently associated with higher mortality during and after ICU care [8]. Even though functional capacity is highly influenced by muscle work, our data showed that admission muscle mass was not significantly associated with disability at hospital discharge [8]. Moreover, while muscle mass substantially contributes to normal body weight [9], the overweight state is largely driven by fat mass [10]. Currently, there is controversy as to whether obese-range weight paradoxically portends a better ICU prognosis [11-13] or not [14-16]. Our previous data indicated that subcutaneous fat mass at the 7 th vertebral level measured at ICU admission was not significantly associated with ICU outcomes [8].

While previous research indicates that muscle mass and bone density decrease as a result of ICU admission $[1,17]$, there is no information regarding the association of critically ill patients' baseline bone density with survival and other patient-centered outcomes. A disaggregated evaluation of body constituents could improve our understanding of their potential pathophysiological contribution to critical illness outcomes.

In the present study, we extended our prior study [8] by analyzing the association of erector spinae muscle, fat mass, and bone density determined within $24 \mathrm{~h}$ of ICU admission with survival and disability at hospital discharge. We chose to measure the antigravity erector spinae muscle (ESM) area given that it is indispensable for upright posture and locomotion, and thus could be associated with both outcome measures, and specifically clarify the association of muscle mass with disability at hospital discharge. Our central hypothesis was that greater admission muscle mass would be the main driver of better ICU outcomes compared with a relatively less impactful effect of bone density and fat mass. To test this hypothesis, muscle mass was determined by the ESM cross-sectional area [18], fat was determined by measuring the subcutaneous adipose tissue (SAT) area at the thoracic 7-8th level areas previously established [19], and bone density was analyzed based on 12th vertebral body attenuation [20]. We also collected follow-up data on the patients' clinical outcomes over time. For the analyses of fat mass, the previously published cohort was expanded with 104 patients.

\section{Materials and methods}

This was a prospective, single-center, observational study of adult subjects admitted to the medical intensive care unit (MICU) of Albany Medical Center. Ethical approval was obtained from Albany Medical College Committee on Research Involving Human Subjects (IRB\# 4281). Enrollment took place between November 2015 and June 2019, and the 6-month survival determination was completed in January 2020. Patients were considered for enrollment if they were older than 18 years, admitted to the MICU, had undergone a chest or abdomen CT scan at admission or were expected to undergo one within the first $24 \mathrm{~h}$ of MICU stay, and were anticipated to require ICU care for longer than $24 \mathrm{~h}$. Exclusion criteria were primary neuromuscular pathology, acute illness leading to imminent death or chronic illness with a life expectancy of shorter than 6 months. Enrollment was attempted on all eligible patients, and written consent was obtained from the patient or a legally authorized representative. Prehospital comorbidities were determined by clinical history and with hospital documentation. Functional independence before admission was defined as the subject's ability to live at home without help. Patients who were living at home with a caregiver, at a nursing home, or at an assisted living facility or who were transferred from a different institution were considered not functionally independent before hospitalization.

Our previous research [8] indicated that 100 events would need to occur to reach a significant association of muscle cross-sectional area with mortality at 6 months [8], which led to a targeted cohort size of 500 patients given a mortality rate of 30\%, a $90 \%$ follow-up efficiency, and an estimate that $20 \%$ of CT scans would not be technically evaluable. Moreover, as in our previous report, we appreciated an underrepresentation of female sex and given that fat area was found significantly larger in these individuals [8]; here, we calculated that 220 female subjects would power the cohort similarly to the male's arm in the previous study regarding the fat area analysis; that number would be achieved, assuming the same proportion of females (44\%), by reaching a target cohort size of 500 participants. Enrolled patients were monitored daily for survival, length of ICU stay, and disposition at discharge. Survival at 6 months was determined either by hospital documentation or phone communication. If 6-month survival could not be determined by these methods, we searched for notifications of patients' death in obituary lists published by local newspapers. To compare the enrolled versus non-enrolled patient populations during the study period, deidentified information including demographic characteristics and the reason for hospitalization of the entire MICU census was provided by the Albany Medical Center Department of Analytics following an IRB waiver. Out of the 507 patients enrolled in this cohort, 403 had been reported in a previous publication [8]; however, the erector spinal muscle and bone CT measurements obtained in this trial had not been previously analyzed or reported. 
Erector spinae muscle (ESM) area measurement was performed as previously established [18] using a single axial slice of the CT scan with an in-house software. In short, a single chest radiologist blinded to the patients' identity and clinical characteristics visually identified the left and right ESMs which were manually shaded, and the ESM cross-sectional area (CSA) was presented as the sum of the right and left muscles expressed in square centimeters (Fig. 1a). Bone density was measured at the T12 level by determining the Hounsfield attenuation units (HU) value as previously established [20] (Fig. 1b), and subcutaneous adipose tissue was measured at the T7-8 vertebral level as previously described [19] (Fig. 1c). These tomographic levels were selected as they simultaneously capture the three body constituents of interest, which can be analyzed with previously described methods and accessed with either chest or abdomen CTs. A more detailed explanation of methods can be found in the supplementary material.

\section{Statistical analysis}

The primary outcome variable was 6-month survival and the secondary outcome variable was disability at hospital discharge. We chose covariables based on previous literature and clinical relevance, and then assessed how they associated with categorical outcome measures using logistic regression models. Outcome-associated variables evaluated on a univariate basis and used in the multivariable model were (1) sex, (2) age, (3) SOFA score, (4) APACHE II score, (5) bone density, (6) fat area, (7) muscle area, (8) mMRC, (9) serum albumin, (10) functional independence before hospitalization, (11) preexisting cancer, (12) pre-existing pulmonary disease, (13) pre-existing congestive heart failure, (14) pre-existing end-stage renal disease in dialysis, and (15) chronic steroid use. For multivariable models, we used a backward elimination approach with alpha to remove set at 0.10 . Variance inflation factors (VIFs) were used to assess multicollinearity. Survival analysis was conducted on quartiles of ESM area using the log-rank test. In addition, the association of ESM with survival time was analyzed by using a Cox proportional hazard model using the same univariate and multivariable approach. Univariate and multivariable logistic regression and survival analysis were performed using Minitab Statistical Software (State College, PA) and JMP (SAS, Cary, NC), with significance accepted at a two-tailed alpha of 0.05 .

Disability at discharge was analyzed using binary logistic regression with discharge location as the two possible outcomes: (1) discharge to a facility or home with assisted living required (discharged not independent) or (2) discharge to home without assisted living required (discharged independent). Comparison of ESM areas between these two groups was made by Mann-Whitney test. Because some patients' CT scans were not analyzable for specific body constituents, univariate analyses were conducted for cases with complete data $(N=422,463$, and 423 for muscle, fat, and bone measurements, respectively). Multivariable analyses were conducted only using cases with complete data for all variables (420 cases).

\section{Results}

A total of $643 \mathrm{MICU}$ patients were considered eligible for this study, of which 507 (79\%) were included and 136 (21\%) were excluded (Fig. 2). Sixty-five patients were later excluded for muscle analysis, 24 for fat analysis, and 63 for bone analysis due to technical limitations in determining these measures on CT leaving 422 cases for muscle, 463 cases for fat, and 423 for bone measurements. Four hundred and twenty cases had all three measures completed. The demographic data are shown in Table 1. The median ESM area was $30 \mathrm{~cm}^{2}$ with an

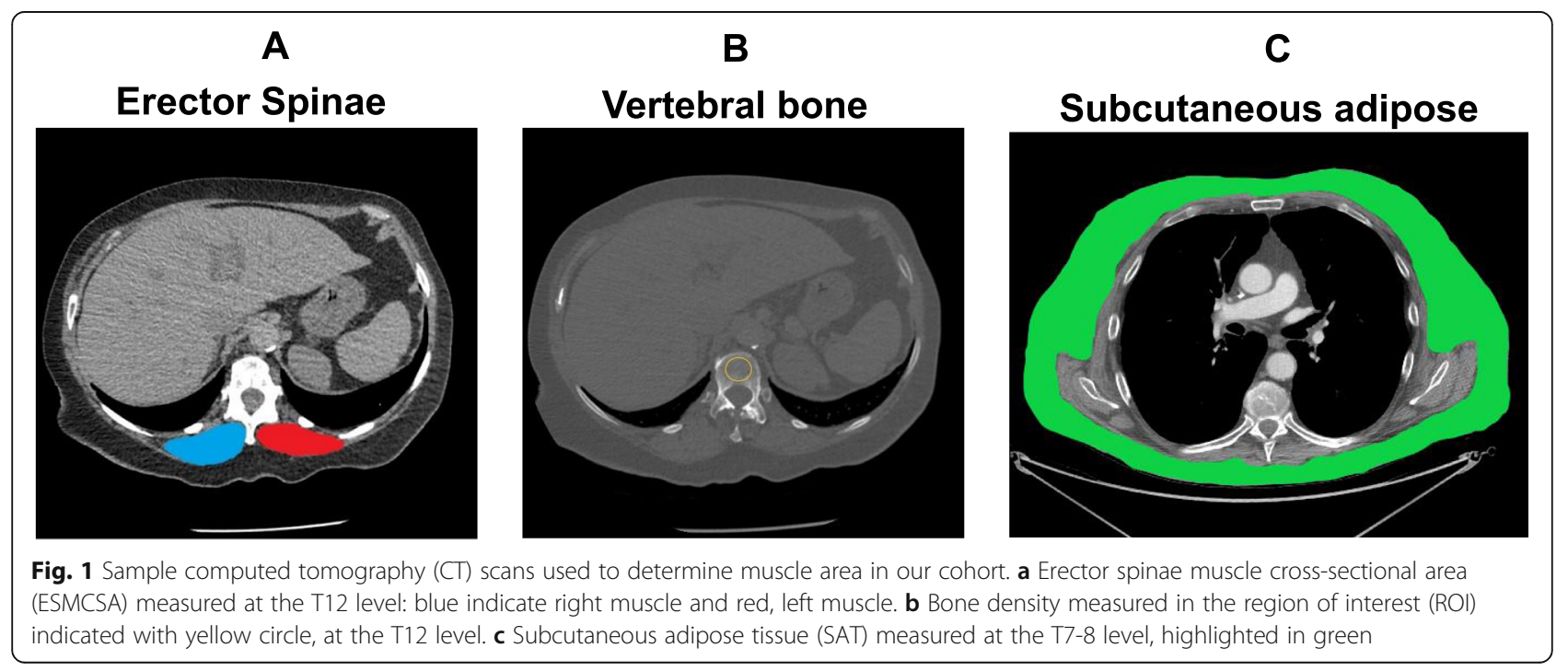




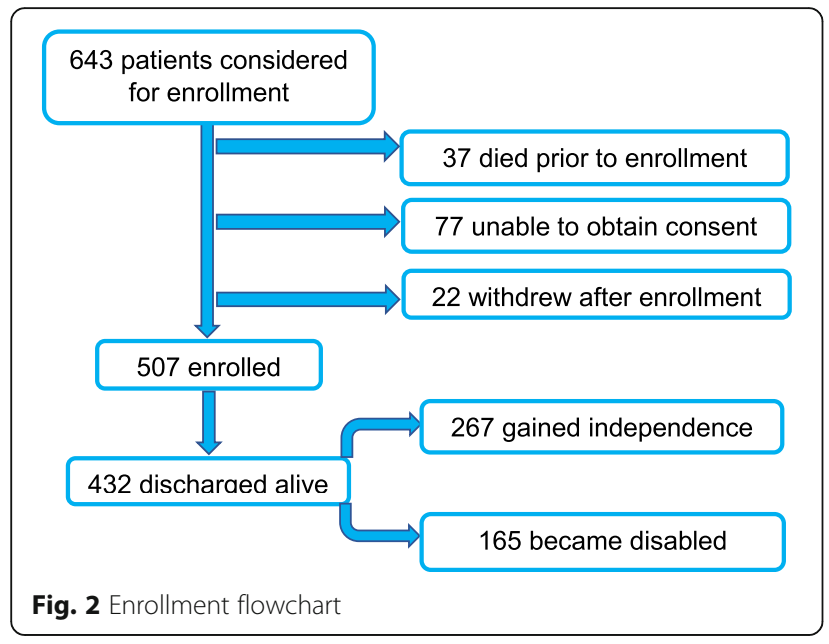

interquartile range of 22.4-38.4. The median SAT was $16.7 \mathrm{~cm}^{2}$ with an interquartile range of $11-26$; and the median bone density was $156 \mathrm{HU}$ with an interquartile range of 118-195. The average age of the cohort was 62 years and there was a slight male predominance (54\%). The unadjusted raw ESM area was smaller in females than males and weakly inversely correlated with age (Table E1). Similarly, a statistically significant negative correlation between bone density and age was found in this cohort (Table E1), which was consistent in magnitude with previously described data [20-22]. Out of the 507 patients enrolled and analyzed, $432(85 \%)$ were discharged alive. Among these survivors, 267 (62\%) were functionally independent and 165 (38\%) were not functionally independent at discharge. At 6 months, 317 patients (62\%) were alive, 168 (33\%) had died, and 22 (5\%) could not be reached to determine status. Although data of these 22 missing patients was obtained to count the number of cases with computed tomography, it was not included in the 6-months survival analyses (Table E2).

\section{Association of admission ESM area with outcomes}

Larger ESM was significantly associated with decreased odds of mortality at 6 months (OR 0.96 per $\mathrm{cm}^{2}$ increase in ESM; 95\% CI 0.94-0.97; $p<0.001$; Table 2). Figure 3a shows Kaplan-Meier curves for patients with muscle areas values divided in 4 quartiles $(p<0.001$; log-rank test). In a multivariable analysis, the association of ESM with mortality persisted even after adjusting for other variables including severity scores, albumin, and mMRC (Table 2). ESM was associated with survival using a Cox proportional hazard model on a univariate basis (RR 0.96 per $\mathrm{cm}^{2}$ of muscle area, CI $0.95-0.98, p<0.001$ ) and in a Cox multivariable model (RR 0.98 per $\mathrm{cm}^{2}$ of muscle, 95\%CI 0.97-0.999 $p=0.04$; Table E3).

Also, among survivors at hospital discharge, greater ESM was significantly associated with decreased odds of
Table 1 Baseline characteristics of the cohort

\begin{tabular}{|c|c|c|}
\hline Demographics & & IQR \\
\hline Male gender & $54 \%$ & NA \\
\hline Muscle area* & 30 & $22.4-38.4$ \\
\hline Fat area & 16.7 & $11-26$ \\
\hline Bone density & 156 & $118-195$ \\
\hline Age & 62 & $51-72$ \\
\hline \multicolumn{3}{|l|}{ Severity Scores } \\
\hline APACHE ॥ & 16 & $11-22$ \\
\hline SOFA & 5 & $3-8$ \\
\hline Preadmission comorbidities & Total & $\%$ \\
\hline Pulmonary disease & 170 & 35 \\
\hline Diabetes & 121 & 25 \\
\hline Steroids use & 112 & 23 \\
\hline Cancer & 106 & 22 \\
\hline Congestive heart failure & 90 & 19 \\
\hline End-stage renal disease & 37 & 7.6 \\
\hline Preadmission mMRC ${ }^{* *}$ & 3 & $1-4$ \\
\hline Primary reason of ICU admission & Total & $\%$ \\
\hline Respiratory failure & 194 & 40 \\
\hline Non-respiratory sepsis & 92 & 19 \\
\hline Pulmonary embolism & 70 & 14 \\
\hline Hemorrhagic shock & 40 & 8 \\
\hline Altered mental status & 23 & 4.7 \\
\hline Metabolic cause including DKA*** & 16 & 3 \\
\hline Cardiovascular decompensation & 16 & 3 \\
\hline Trauma & 11 & 2 \\
\hline Other & 21 & 4.5 \\
\hline Residence before ICU admission & Total & $\%$ \\
\hline Living at home independently & 261 & 54 \\
\hline Living with caregiver & 64 & 13 \\
\hline Transferred from another hospital & 60 & 12 \\
\hline Living at assisted living facility & 37 & 7 \\
\hline Living at hospice & 33 & 6 \\
\hline Unknown & 28 & 5 \\
\hline
\end{tabular}

*Median value of ESM; females' areas were multiplied by 1.67 in this analysis **mMRC, modified medical research council dyspnea score interquartile range (IQR)

***DKA, diabetic ketoacidosis

Total number of patients and percentages are calculated based on 483 cases, which is the number of CT scans that could be used for adipose tissue analysis. Notice that these figures were slightly different in muscle and bone measurements due to technical limitations in these determinations (see main text for details). "Preadmission comorbidities" is a category that admits more than one item per patient; reason for admission is a category that only admits one item per patient. APACHE Acute Physiology and Chronic Health Evaluation II score, SOFA Sequential Organ Failure Assessment score

disability (OR 0.98 per $\mathrm{cm}^{2}$ ESM; $95 \%$ CI $0.96-0.99 ; p=$ 0.012; Table 2). Figure $3 \mathrm{~b}$ compares muscle areas in those discharged functionally independent versus not 
Table 2 Univariate and multivariate associations of analyzed covariables with 6 months survival (primary outcome) and disability at hospital discharge (secondary outcome)

\begin{tabular}{|c|c|c|c|}
\hline Variable (per unit change unless otherwise indicated) & Odds ratio & $95 \% \mathrm{Cl}$ & $p$ \\
\hline Age (per decade) & 1.29 & $(1.13,1.46)$ & $<0.001$ \\
\hline Albumin & 0.33 & $(0.24,0.45)$ & $<0.001$ \\
\hline SOFA & 1.19 & $(1.13,1.26)$ & $<0.001$ \\
\hline APACHE ॥ & 1.10 & $(1.07,1.13)$ & $<0.001$ \\
\hline Bone density (per $100 \mathrm{HU}$ ) & 0.69 & $(0.49,0.96)$ & 0.03 \\
\hline ESMCSA (muscle area, per $\mathrm{cm}^{2}$ ) & 0.96 & $(0.94,0.97)$ & $<0.001$ \\
\hline Fat $\left(\right.$ per $10 \mathrm{~cm}^{2}$ ) & 0.99 & $(0.97,1.01)$ & 0.19 \\
\hline Sex M/F & 1.39 & $(0.95,2.03)$ & 0.09 \\
\hline $\mathrm{mMRC}$ & 1.36 & $(1.20,1.55)$ & 0.011 \\
\hline Not independent at admission & 1.52 & $(1.03,2.24)$ & 0.04 \\
\hline Cancer & 4.00 & $(2.57,6.24)$ & $<0.001$ \\
\hline Congestive heart failure & 1.36 & $(0.85,2.16)$ & 0.2 \\
\hline Chronic pulmonary disease & 1.12 & $(0.76,1.65)$ & 0.56 \\
\hline End-stage renal disease & 2.11 & $(1.09,4.08)$ & 0.03 \\
\hline Chronic steroids & 1.09 & $(0.71,1.70)$ & 0.69 \\
\hline \multicolumn{4}{|c|}{ Multivariable risk factors for 6-month mortality (primary outcome) } \\
\hline Variables included in the model & Odds Ratio & $95 \% \mathrm{Cl}$ & $p$ \\
\hline APACHE ॥ & 1.06 & $(1.01,1.11)$ & 0.01 \\
\hline SOFA & 1.10 & $(1.01,1.20)$ & 0.04 \\
\hline Albumin & 0.49 & $(0.33,0.72)$ & $<0.001$ \\
\hline ESMCSA (muscle area, per $\mathrm{cm}^{2}$ ) & 0.98 & $(0.96,0.99)$ & 0.03 \\
\hline mMRC & 1.20 & $(1.02,1.42)$ & 0.03 \\
\hline Cancer & 3.25 & $(1.86,5.69)$ & $<0.001$ \\
\hline \multicolumn{4}{|c|}{ Univariate associations for disability at discharge (secondary outcome) } \\
\hline Variable (per unit change unless otherwise indicated) & Odds Ratio & $95 \% \mathrm{Cl}$ & $p$ \\
\hline Age (per decade) & 1.45 & $(1.26,1.66)$ & $<0.001$ \\
\hline Albumin & 0.51 & $(0.38,0.69)$ & $<0.001$ \\
\hline SOFA & 1.11 & $(1.04,1.17)$ & 0.001 \\
\hline APACHE ॥ & 1.06 & $(1.03,1.09)$ & $<0.001$ \\
\hline Bone density (per $100 \mathrm{HU}$ ) & 0.52 & $(0.37,0.74)$ & 0.01 \\
\hline ESMCSA (muscle area, per $\mathrm{cm}^{2}$ ) & 0.98 & $(0.96,0.99)$ & 0.012 \\
\hline Fat $\left(\right.$ per $\left.10 \mathrm{~cm}^{2}\right)$ & 1.01 & $(0.994,1.03)$ & 0.13 \\
\hline Sex M/F & 0.76 & $(0.52,1.13)$ & 0.18 \\
\hline mMRC & 1.40 & $(1.23,1.60)$ & $<0.001$ \\
\hline Not independent at admission & 3.56 & $(2.35,5.39)$ & $<0.001$ \\
\hline Cancer & 1.27 & $(0.78,2.06)$ & 0.34 \\
\hline Congestive heart failure & 1.48 & $(0.90,2.44)$ & 0.13 \\
\hline Chronic pulmonary disease & 1.25 & $(0.84,1.87)$ & 0.28 \\
\hline End-stage renal disease & 1.18 & $(0.56,2.47)$ & 0.66 \\
\hline Chronic steroids & 1.03 & $(0.65,1.63)$ & 0.91 \\
\hline \multicolumn{4}{|c|}{ Multivariable risk factors for disability at discharge (secondary outcome) } \\
\hline Variable & Odds Ratio & $95 \% \mathrm{Cl}$ & $p$ \\
\hline Age (per decade) & 1.29 & $(1.09,1.52)$ & $<0.001$ \\
\hline
\end{tabular}


Table 2 Univariate and multivariate associations of analyzed covariables with 6 months survival (primary outcome) and disability at hospital discharge (secondary outcome) (Continued)

$\begin{array}{llll}\text { APACHE II } & 1.04 & (1.01,1.08) & \mathbf{0 . 0 2} \\ \text { mMRC } & 1.18 & (1.004,1.40) & \mathbf{0 . 0 4 5} \\ \text { Albumin } & 0.56 & (0.38,0.83) & <\mathbf{0 . 0 0 1} \\ \text { Not independent at admission } & 2.79 & (1.71,4.54) & <\mathbf{0 . 0 0 1}\end{array}$

Fat magnitude expresses subcutaneous adipose tissue (SAT) area; ESMCSA erector spinae muscle cross-sectional area, mMRC modified medical research council dyspnea score

functionally independent. Multivariable modeling indicated that the statistically significant association of muscle mass with disability at discharge was lost after adjusting for other significant covariables including severity score (Table 2).

\section{Association of admission bone density with outcomes}

Higher bone density was significantly associated with decreased odds of mortality at 6 months (OR 0.69 per 100 HU increase in bone density; 95\% CI 0.49-0.96 $p<$ $0.027)$. However, in a multivariable analysis, the association of bone density with mortality lost its statistical significance after adjusting for other covariables including severity score (Table 2). Also, among survivors at hospital discharge, reduced bone density was significantly associated with decreased odds of disability (OR 0.52 per $100 \mathrm{HU}$; 95\% CI 0.37-0.74; $p<0.001)$. Multivariable modeling demonstrated that this association was no longer significant after adjusting for different covariables including severity score (Table 2).

\section{Association of admission subcutaneous adipose tissue (SAT) with outcomes}

There was no statistically significant association between SAT and survival at 6 months (OR 0.99; 95\% CI 0.97$1.01 ; p=0.19$ ) or disability at hospital discharge (OR 1.01 ; 95\% CI 0.99-1.03; $p=0.13$ ).

\section{Discussion}

In this prospective cohort study of critically ill patients, we found a significant association of larger admission erector spinae muscle (ESM) area with higher 6-month survival. Consistent with the antigravity effect of erector spinae muscles which is indispensable to maintain the upright posture needed for locomotion, greater ESM area was also associated with regaining independent function at discharge versus the need for assisted living. This association with disability at discharge was not found in our previous analysis of the non-locomotor pectoralis muscle area. The associations of muscle area with survival persisted even after adjusting for severity score, age, albumin, exercise limitation represented by modified Medical Research Council dyspnea score (mMRC), and other variables. By contrast, the association between muscle mass and disability at discharge was not statistically significant after including associations with other variables in the multivariable analysis. Our data also indicates that while higher bone density associates with better survival and less disability at hospital discharge, these correlations become insignificant after correcting for other covariables including severity score and muscle mass. Fat area was not found associated with the mortality and disability outcomes.

While the effects of critical illness on bone density and fracture risk have been described [17, 23, 24], to our knowledge, this is the first analysis that evaluates the associations of baseline bone density with survival and disability associated with critical illness, especially accounting for other relevant body mass components. Previous evidence indicates that higher preadmission weight associates with better post-ICU status [25]; however, it is unclear which body constituent accounted for the weight's salutatory effect in that study. Indeed, it has been reported that obesity associates with greater survival in critical illness $[11,26]$ and that morbid obesity does not associate with worse outcomes [14]. Therefore, it is plausible that fat, and not muscle or bone, contributes to better prognosis. While a recent retrospective study involving 25 patients suggests that baseline body composition including fat and muscle is not associated with ICU length of stay [27], no evaluation of survival was reported and the small sample size of that cohort precluded analyses combining relevant covariables. Our data suggests that subcutaneous adipose tissue has no association with outcomes and that it is the contribution of muscle to body weight rather than fat or bone that is independently associated with survival.

The main strengths of this study are the large size of our cohort and the prospective study design. In addition, the simultaneous determination of major body constituents allowed for accurate analysis of the interplay of these variables' effects on survival and disability at discharge. The selection of the erector spinae muscle, which is easily measurable [18] and needed for locomotion [28], allows for assessment of the systemic/global effects of muscle wasting on ICU outcomes combined with disability at discharge. Furthermore, ESM area is accessible via $\mathrm{CT}$ chest and abdomen which expands its potential use the in the ICU setting, has both type I (oxidative) and II (glycolytic) fibers [28], and thus reflects 
A

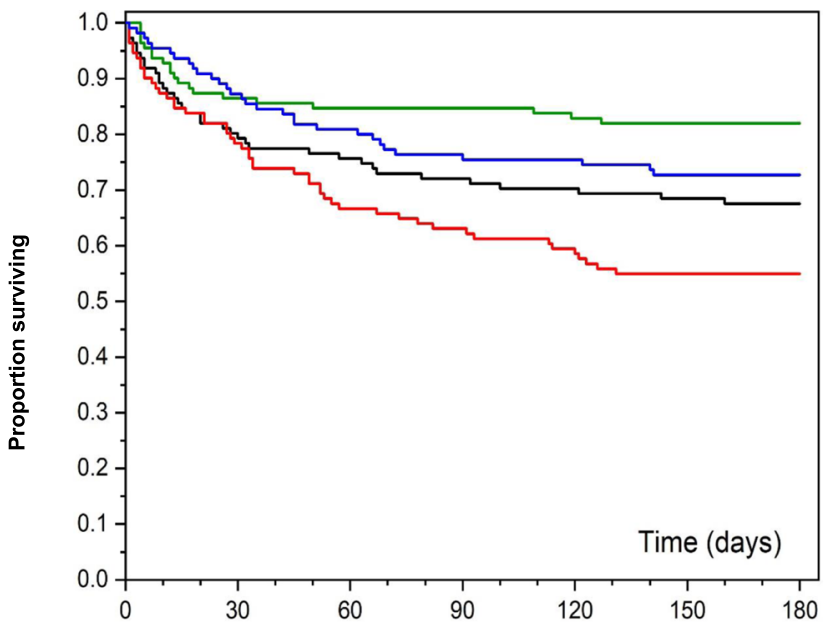

\begin{tabular}{|c|c|c|c|c|c|c|c|}
\hline \multicolumn{8}{|c|}{ Number at Risk- by quartile } \\
\hline 4th & 111 & 97 & 95 & 95 & 93 & 93 & 92 \\
\hline 3rd & 110 & 97 & 90 & 85 & 84 & 81 & 81 \\
\hline 2nd & 111 & 89 & 85 & 81 & 79 & 77 & 76 \\
\hline 1st & 111 & 88 & 75 & 71 & 66 & 62 & 62 \\
\hline
\end{tabular}

B

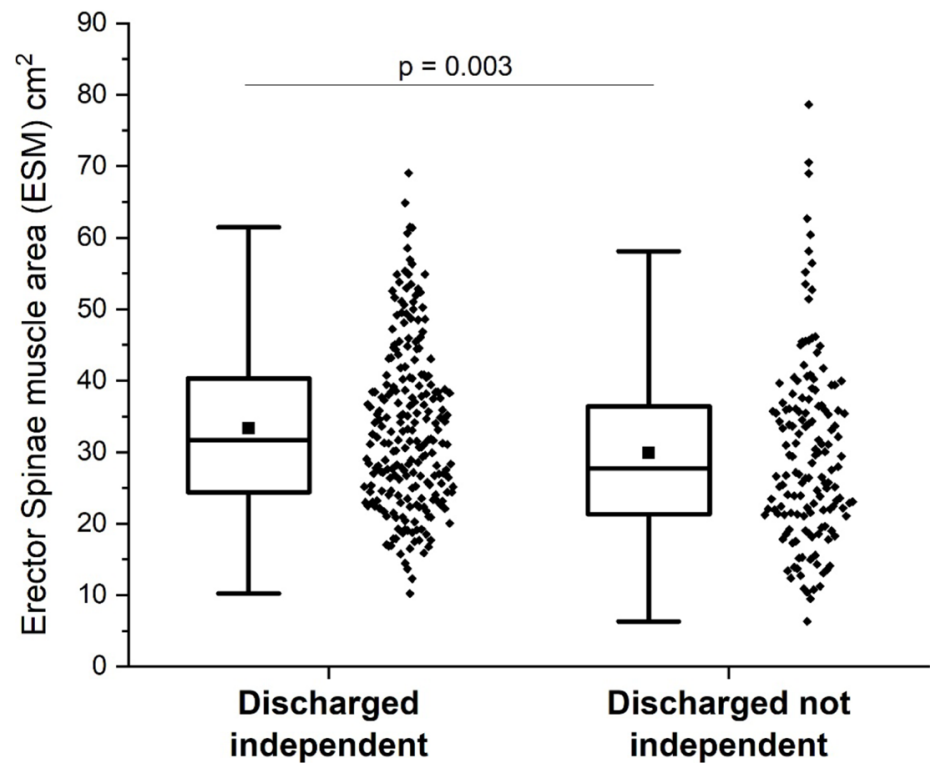

Fig. 3 a Kaplan-Meier survival at 6 months based on ESCSA. Comparison of survival rate between patients with erector spinae muscle (ESM) cross-sectional area below divided in 4 quartiles. 1st quartile, red; 2nd quartile, black; 3rd quartile, blue; and 4th quartile, green $(p<0.001$; log-rank test). At 6 months, 317 patients were alive, 168 had died, and 22 could not be reached to determine status. Female ESM was multiplied by 1.67 in this analysis (see supplement for details). b Distribution of erector spinae muscle CSA (in $\mathrm{cm}^{2}$ ) stratified by disposition at discharge. Comparison between groups was done with non-parametric Mann-Whitney test $(p=0.003)$. The groups are different with discharged independent $(n=231)$ greater than not independent $(n=150)$. See definition of discharged independent and not independent in the "Materials and methods" section. Female ESM area was multiplied by 1.67 in this analysis. For box plots, center line is median, upper and lower lines are 75 th and 25th percentile, and whiskers are the non-outlier range $(<1.5$ IQR from box $)$ 
muscle wasting even in the presence of comorbidities that demonstrate selective fiber-type atrophy [29].

Our study has some limitations. First, it was performed at a single institution, and although the admission diagnoses of our cohort were diverse, it is possible that the distribution of diagnoses is not generalizable to other ICUs. Second, CT scans were performed for a clinical indication and not as part of a study protocol. Because certain diagnoses are more frequently evaluated by chest and abdomen CT scan than others, a selection bias could not be avoided, and as shown by Tables E5, E6, E7, there were significant differences in the indications for ICU admission in our cohort versus the general census during the enrollment period. However, our study population is similar to other major studies' in the field: a recent systematic review of prospective data involving 31 studies and 3905 patients focused on ICU-associated muscle dysfunction [30] found that 39\% of ICU admissions were due to respiratory failure (40\% in our study), $15 \%$ were due to sepsis (19\% in our study), and average patient age was 61 years old (62 in our study). Third, while previous research has investigated lumbar muscle mass in ICU patients [31], the use of the ESM area surrogate has not been validated in this population, although it has been used in this fashion in healthy and chronically ill patients $[18,28]$. Likewise, while fat/SAT measurement at the thoracic 7-8 level has not been validated for ICU patients, it has shown to be highly correlated with the thoracic adipose tissue volume and with body mass index [19]. CT scan bone density has been previously used in critical illness and other settings [21, 32], and although it has comparable performance to dual X-ray absorptiometry (DXA) scan at the femoral neck level [33], it has not been validated in the ICU setting. Fourth, because patients were enrolled after they had already developed critical illness, we had to select a surrogate measure of prehospitalization mobility status. While previous research has used simple surrogates of preadmission exercise capacity such as the patients' relatives-reported ability to ambulate up 10 stairs before hospitalization [34], we chose the mMRC score because of its simplicity, high interobserver agreement, and adequate correlation with other scoring systems [35] (Table E8-9). We realize that the mMRC is potentially confounded by cardiopulmonary limitations and other factors. However, as many of our patients were unable to cooperate with the evaluation, volitional tests such as MRC muscle strength scores [7] or other direct muscle evaluations [36] were not feasible. Fifth, the stratification of disability at discharge was based on the discharge location which does not directly address the subject's functional capacity at that timepoint. Future research to address the association between muscle mass and activities of daily living (ADLs) at hospital discharge will add more granularity to this issue. Sixth, the used multivariable modeling was intended to define specific associations of body constituents with outcome measures, which could imply that unmeasured confounding and residual bias cannot be excluded.

\section{Conclusion}

In summary, our data suggests that admission ESM area and bone density of ICU patients are associated with 6month survival and with disability at hospital discharge. Larger muscle area is the only body weight constituent that persists significantly associated with survival even after multivariable adjustments; yet it does not persist associated with disability at discharge after these adjustments. Fat area is not associated with the analyzed outcomes variables. Because these outcomes are highly relevant, we postulate that further investigation may clarify whether better muscle mass can lead to improved outcomes. Our data supports the rationale of conducting mechanistic research focused on skeletal muscle integrity to interrogate its potential benefits to improve ICU prognosis [37-44].

\section{Supplementary information}

Supplementary information accompanies this paper at https://doi.org/10. 1186/s13054-020-03276-9.

Additional file 1: Table E1: Erector spinae muscle (ESM) cross sectional area and bone density associations with age.

Additional file 2: Table E2: Disposition of enrolled patients.

Additional file 3: Table E3: Survival analysis using the Cox proportional hazard determination, both univariate (above) and multivariate (below).

Additional file 4: Table E4: Correction of females' muscle sizes by ideal body weight (IBW) using Devine's formula and adjustment factor 1.67.

Additional file 5: Table E5: Primary indications of ICU admission in our cohort (based on 483 images used to measure subcutaneous adipose tissue as reference) versus the general MICU census (minus the patients from our cohort) during the enrollment period.

Additional file 6: Table E6: Primary indications of ICU admission in our cohort (based on 483 images used to measure subcutaneous adipose tissue as reference) versus the general MICU census during the enrollment period.

Additional file 7: Table E7: Primary indication of chest and abdomen CT scans in our cohort, based on 483 images used to measure subcutaneous adipose tissue as reference.

Additional file 8: Table E8: Modified Medical Research Council (mMRC) dyspnea score.

Additional file 9: Table E9: $\mathrm{mMRC}$ determination in our cohort. Additional file 10: Table E10: Intra observer muscle, bone and fat variabilities.

\section{Acknowledgements}

The authors thank Brendan Philbin and William Rauch (Department of Analytics) for the diligent work providing data from non-enrolled patients. We also thank Dr. Eitel J.M. Lauría, PhD, for his insight regarding multivariate modeling of the reported data. 


\section{Authors' contributions}

$\mathrm{AJ}$ and MHSK screened eligible patients, and AJ, MHSK, Rl, and HC enrolled them. CD made the CT scan measurements, and JF confirmed them. MHSK and AN followed up on patients' outcomes. PF performed statistical analyses. $\mathrm{AJ}, \mathrm{JBH}, \mathrm{PF}$, and MAJ designed the trial, and $\mathrm{AJ}, \mathrm{JBH}$, and MAJ wrote and edited the paper. The authors read and approved the final manuscript.

\section{Funding}

Part of the results reported herein have been funded by NHLBI of the National Institutes of Health under the award number K01-HL130704 (AJ) and by the Collins Family Foundation Endowment (AJ).

\section{Availability of data and materials}

The datasets generated during and/or analyzed during the current study are not publicly available due to IRB provisions but are available from the corresponding author on reasonable request.

\section{Ethics approval and consent to participate}

Ethical approval was obtained from Albany Medical College Committee on Research Involving Human Subjects (IRB\# 4281).

\section{Consent for publication}

Patients agreed to allow all the manuscript data to be reported in a deidentified way.

\section{Competing interests}

Authors declare no conflicts of interest related to this manuscript content.

\section{Author details}

'Division of Pulmonary and Critical Care Medicine, Albany Medical College, Albany, NY, USA. 'Department of Molecular and Cellular Physiology, Albany Medical College, 47 New Scotland Av, Albany, NY, USA. ${ }^{3}$ Department of Radiology, Albany Medical College, Albany, NY, USA. ${ }^{4}$ Present Address: Division of Pulmonary and Critical Care Medicine Spectrum Health-Michigan State University College of Human Medicine, Grand Rapids, MI, USA. ${ }^{5}$ Section of Pulmonary and Critical Care, Department of Medicine, University of Chicago, Chicago, IL, USA. ${ }^{6}$ Department of Neuroscience and Experimental Therapeutics, Albany Medical College, Albany, NY, USA.

Received: 25 May 2020 Accepted: 4 September 2020

Published online: 21 September 2020

\section{References}

1. Puthucheary ZA, Rawal J, McPhail M, et al. Acute skeletal muscle wasting in critical illness. JAMA. 2013;310(15):1591-600.

2. Jaitovich A, Barreiro E. Skeletal muscle dysfunction in chronic obstructive pulmonary disease. What we know and can do for our patients. Am J Respir Crit Care Med. 2018;198(2):175-86.

3. Ali NA, O'Brien JM Jr, Hoffmann SP, et al. Acquired weakness, handgrip strength, and mortality in critically ill patients. Am J Respir Crit Care Med. 2008;178(3):261-8.

4. Sharshar T, Bastuji-Garin S, Stevens RD, et al. Presence and severity of intensive care unit-acquired paresis at time of awakening are associated with increased intensive care unit and hospital mortality. Crit Care Med. 2009;37(12):3047-53.

5. Kress JP, Hall JB. ICU-acquired weakness and recovery from critical illness. N Engl J Med. 2014;370(17):1626-35.

6. Herridge MS, Cheung AM, Tansey CM, et al. One-year outcomes in survivors of the acute respiratory distress syndrome. N Engl J Med. 2003;348(8):683-93.

7. Dos Santos C, Hussain SN, Mathur S, et al. Mechanisms of chronic muscle wasting and dysfunction after an intensive care unit stay. A pilot study. Am J Respir Crit Care Med. 2016;194(7):821-30.

8. Jaitovich A, Khan M, Itty R, et al. ICU admission muscle and fat mass, survival, and disability at discharge: a prospective cohort study. Chest. 2019; 155(2):322-30.

9. Basaria S, Coviello AD, Travison TG, et al. Adverse events associated with testosterone administration. N Engl J Med. 2010;363(2):109-22.

10. Sharma K, Mogensen KM, Robinson MK. Under-recognizing malnutrition in hospitalized obese populations: the real paradox. Curr Nutr Rep. 2019;8(4): 317-22.
11. O'Brien JM Jr, Phillips GS, Ali NA, et al. Body mass index is independently associated with hospital mortality in mechanically ventilated adults with acute lung injury. Crit Care Med. 2006;34(3):738-44.

12. Pepper DJ, Demirkale CY, Sun J, et al. Does obesity protect against death in Sepsis? A retrospective cohort study of 55,038 adult patients. Crit Care Med. 2019:47(5):643-50.

13. Hogue CW Jr, Stearns JD, Colantuoni E, et al. The impact of obesity on outcomes after critical illness: a meta-analysis. Intensive Care Med. 2009; 35(7):1152-70

14. Martino JL, Stapleton RD, Wang M, et al. Extreme obesity and outcomes in critically ill patients. Chest. 2011;140(5):1198-206.

15. Paolini JB, Mancini J, Genestal M, et al. Predictive value of abdominal obesity vs. body mass index for determining risk of intensive care unit mortality. Crit Care Med. 2010;38(5):1308-14.

16. Global, B.M.I.M.C, Di Angelantonio E, Sh NB, et al. Body-mass index and allcause mortality: individual-participant-data meta-analysis of 239 prospective studies in four continents. Lancet. 2016;388(10046):776-86.

17. Orford NR, Lane SE, Bailey M, et al. Changes in bone mineral density in the year after critical illness. Am J Respir Crit Care Med. 2016;193(7):736-44.

18. Tanimura K, Sato S, Fuseya Y, et al. Quantitative assessment of erector spinae muscles in patients with chronic obstructive pulmonary disease. Novel chest computed tomography-derived index for prognosis. Ann Am Thorac Soc. 2016:13(3):334-41.

19. Tong Y, Udupa JK, Torigian DA, et al. Chest fat quantification via $C T$ based on standardized anatomy space in adult lung transplant candidates. PLoS One. 2017;12(1):e0168932.

20. de Jong $W U$, de Jong PA, Vliegenthart $R$, et al. Association of chronic obstructive pulmonary disease and smoking status with bone density and vertebral fractures in male lung cancer screening participants. J Bone Miner Res. 2014;29(10):2224-9.

21. Gonzalez, G., G.R. Washko, and R.S.J. Estepar, Deep learning for biomarker regression: application to osteoporosis and emphysema on chest $C T$ scans. Proc SPIE Int Soc Opt Eng, 2018. 10574:1-19.

22. Steiger $\mathrm{P}$, Block JE, Steiger $\mathrm{S}$, et al. Spinal bone mineral density measured with quantitative $C T$ : effect of region of interest, vertebral level, and technique. Radiology. 1990;175(2):537-43.

23. Orford NR, Bailey M, Bellomo R, et al. The association of time and medications with changes in bone mineral density in the 2 years after critical illness. Crit Care. 2017;21(1):69.

24. Orford NR, Bailey M, Bellomo R, et al. Changes in bone mineral density in women before critical illness: a matched control nested cohort study. Arch Osteoporos. 2018;13(1):119.

25. Ferrante LE, Pisani MA, Murphy TE, et al. Factors associated with functional recovery among older intensive care unit survivors. Am J Respir Crit Care Med. 2016;194(3):299-307.

26. Shashaty MG, Stapleton RD. Physiological and management implications of obesity in critical illness. Ann Am Thorac Soc. 2014;11(8):1286-97.

27. Dusseaux MM, Antoun S, Grigioni S, et al. Skeletal muscle mass and adipose tissue alteration in critically ill patients. PLoS One. 2019;14(6):e0216991.

28. Agten A, Stevens S, Verbrugghe J, et al. Biopsy samples from the erector spinae of persons with nonspecific chronic low back pain display a decrease in glycolytic muscle fibers. Spine J. 2019;20:199-206.

29. Ciciliot S, Rossi AC, Dyar KA, et al. Muscle type and fiber type specificity in muscle wasting. Int J Biochem Cell Biol. 2013;45(10):2191-9.

30. Fan E, Cheek F, Chlan L, et al. An official American Thoracic Society clinical practice guideline: the diagnosis of intensive care unit-acquired weakness in adults. Am J Respir Crit Care Med. 2014;190(12):1437-46.

31. Weijs PJ, Looijaard WG, Dekker IM, et al. Low skeletal muscle area is a risk factor for mortality in mechanically ventilated critically ill patients. Crit Care. 2014;18(2):R12.

32. Hongo $\mathrm{T}$, Kotake $\mathrm{K}$, Muramatsu $\mathrm{H}$, et al. Loss of bone mineral density following sepsis using Hounsfield units by computed tomography. Acute Med Surg. 2019;6(2):173-9.

33. Lim HK, Ha HI, Park SY, et al. Comparison of the diagnostic performance of CT Hounsfield unit histogram analysis and dual-energy X-ray absorptiometry in predicting osteoporosis of the femur. Eur Radiol. 2019;29(4):1831-40.

34. Detsky ME, Harhay MO, Bayard DF, et al. Discriminative accuracy of physician and nurse predictions for survival and functional outcomes 6 months after an ICU admission. JAMA. 2017:317(21):2187-95. 
35. Mahler DA, Wells CK. Evaluation of clinical methods for rating dyspnea. Chest. 1988;93(3):580-6.

36. Hough CL, Lieu BK, Caldwell ES. Manual muscle strength testing of critically ill patients: feasibility and interobserver agreement. Crit Care. 2011;15(1):R43.

37. Balnis J, Korponay TC, Vincent CE, et al. IL-13-driven pulmonary emphysema leads to skeletal muscle dysfunction attenuated by endurance exercise. J Appl Physiol (1985). 2020;128(1):134-48.

38. Files DC, D'Alessio FR, Johnston LF, et al. A critical role for muscle ring finger-1 in acute lung injury-associated skeletal muscle wasting. Am J Respir Crit Care Med. 2012;185(8):825-34.

39. Files DC, Liu C, Pereyra A, et al. Therapeutic exercise attenuates neutrophilic lung injury and skeletal muscle wasting. Sci Transl Med. 2015;7(278):278ra32.

40. Jaitovich A, Angulo M, Lecuona E, et al. High CO2 levels cause skeletal muscle atrophy via AMP-activated kinase (AMPK), FoxO3a protein, and muscle-specific ring finger protein 1 (MuRF1). J Biol Chem. 2015;290(14): 9183-94.

41. Korponay TC, Balnis J, Vincent CE, et al. High CO2 Downregulates skeletal muscle protein anabolism via AMP-activated protein kinase alpha2mediated depressed ribosomal biogenesis. Am J Respir Cell Mol Biol. 2020; 62(1):74-86.

42. Puthucheary ZA, McNelly AS, Rawal J, et al. Rectus Femoris cross-sectional area and muscle layer thickness: comparative markers of muscle wasting and weakness. Am J Respir Crit Care Med. 2017;195(1):136-8.

43. Puthucheary ZA, Phadke R, Rawal J, et al. Qualitative ultrasound in acute critical illness muscle wasting. Crit Care Med. 2015;43(8):1603-11.

44. Balnis J, Vincent CE, Jones AJ, et al. Established Biomarkers of Chronic Obstructive Pulmonary Disease Reflect Skeletal Muscle Integrity's Response to Exercise in an Animal Model of Pulmonary Emphysema. Am J Respir Cell Mol Biol. 2020;63(2):266-9.

\section{Publisher's Note}

Springer Nature remains neutral with regard to jurisdictional claims in published maps and institutional affiliations.

Ready to submit your research? Choose BMC and benefit from:

- fast, convenient online submission

- thorough peer review by experienced researchers in your field

- rapid publication on acceptance

- support for research data, including large and complex data types

- gold Open Access which fosters wider collaboration and increased citations

- maximum visibility for your research: over $100 \mathrm{M}$ website views per year

At $\mathrm{BMC}$, research is always in progress.

Learn more biomedcentral.com/submissions 